\title{
Concomitant Treatment of Hypertensive Patients with Bisoprolol and Perindopril in Routine Clinical Practice: A Post Hoc Analysis of the CONFIDENCE II, PROTECT I, and PROTECT III Observational Studies
}

Murielle Abeel · Anil Gupta · Christian Constance

Received: August 25, 2021 / Accepted: October 8, 2021 / Published online: November 10, 2021

(C) The Author(s) 2021

\begin{abstract}
Introduction: The combination of angiotensinconverting enzyme inhibitors and beta-blockers is recommended in a wide range of patients with hypertension, including those with stable coronary artery disease and/or elevated heart rate. This post hoc analysis of three observational studies provides effectiveness and safety data on treatment with perindopril on top of bisoprolol-based therapy, in routine clinical practice.

Methods: Data were analyzed from three openlabel, prospective, multicenter, observational studies of Canadian patients with mild-tomoderate hypertension, which shared the same inclusion and exclusion criteria, treatment duration, and primary outcome. This post hoc analysis focused on the subpopulation of patients treated with perindopril on top of bisoprolol-based therapy. All patients were followed for 16 weeks and underwent baseline, week 4, and week 16 visits. Primary outcomes
\end{abstract}

M. Abeel ( $\square)$

Institut de Recherches Internationales Servier (IRIS),

Paris, France

e-mail: murielle.abeel@servier.com

A. Gupta

Trillium Health Partners, Mississauga, ON, Canada

C. Constance

Department of Medicine, University of Montreal,

Quebec, Canada were mean changes in blood pressure (BP) and proportion of patients achieving BP control $(<140 / 90 \mathrm{mmHg})$ in the full analysis set (FAS). Results: A total of 845 patients (mean age $68.3 \pm 11.3$ years, mean baseline BP 151.5/ $86.0 \mathrm{mmHg}$ ) were analyzed in the FAS. After 16 weeks, mean SBP/DBP decreased by $-20.4 /-9.8 \mathrm{mmHg}$ with statistically significant reductions observed at all visits in all three studies allowing $78 \%$ of patients to achieve the BP treatment goal. No statistically significant changes in heart rate were observed and no serious adverse events reported. The most frequent doses of bisoprolol and perindopril were $5+4 \mathrm{mg} \quad(34.9 \%)$, followed by $5+8 \mathrm{mg}$ (16.9\%), and $2.5+4 \mathrm{mg}(12.5 \%)$.

Conclusion: The addition of perindopril on top of bisoprolol-based therapy in patients with mild-to-moderate hypertension was associated with significant reductions in BP compared with baseline and with achievement of BP targets in the majority of patients. The results suggest this strategy is safe and effective for use in routine clinical practice. 


\section{Key Summary Points}

Why carry out this study?

Although there is considerable rationale for combining angiotensin-converting enzyme inhibitors (ACEI) with betablockers (BB), to date the evidence base regarding the effectiveness and safety of a combination of a BB with an ACEI in the treatment of patients with hypertension is small. Perindopril and bisoprolol target different pathways in the pathogenesis and progression of hypertension and both provide 24-h efficacy with once-a-day dosing making them good options for use in combination.

This retrospective post hoc analysis combined data from three large observational studies with the same design to evaluate the effectiveness and safety of treatment with perindopril on top of bisoprolol-based therapy in a large population of patients, in routine clinical practice.

\section{What was learned from the study?}

The addition of perindopril to bisoprololbased therapy was associated with statistically significant reductions in blood pressure compared with baseline after 16 weeks of treatment.

At least three out of four patients with hypertension achieved blood pressure treatment goals at the end of the study and treatment was well tolerated.

Addition of perindopril on top of bisoprolol-based therapy is a safe and effective option for use in routine clinical practice.

\section{INTRODUCTION}

The causes of elevated blood pressure (BP) are multifactorial, making it unlikely that a single antihypertensive agent with one mechanism of action will be able to normalize levels [1]. Clinical guidelines for the management of hypertension now strongly underline the importance of optimizing treatment by initiating therapy with combination treatment in most patients, and tailoring treatment to individual patients on the basis of their hypertension profile and level of cardiovascular risk $[2,3]$. In addition to achieving greater reductions in BP compared with uptitration of the dose of a single drug [4], the use of combination therapy regimens as first-line treatment offers other advantages including a faster reduction in BP and a greater possibility of achieving target, improved tolerability due to use of lower dosages of individual components, and improved patient adherence [5].

The 2018 European Society of Cardiology (ESC)/European Society of Hypertension (ESH) Guideline recommendations for initial dual treatment combinations include an angiotensin-converting enzyme (ACE) inhibitor or angiotensin receptor blocker (ARB) with either a calcium channel blocker (CCB) or diuretic [3]. In patients with hypertension and chronic coronary syndromes, angina, or chronic heart failure with reduced ejection fraction, betablockers, except if contraindicated, should be included in the therapeutic strategy. They should also form part of the strategy at any stage of treatment when they are specifically indicated, e.g., post-myocardial infarction and for heart rate (HR) control [3]. The combination of beta-blockers with ACE inhibitors plays a major therapeutic and preventive role in the management of coronary artery disease (CAD) and heart failure [6, 7], and many patients receive treatment with both agents in routine clinical practice [8]. Among ACE inhibitors, perindopril is supported by substantial efficacy and safety data from large, randomized outcome studies [9-11]. Among beta-blockers, bisoprolol has shown a significant mortality benefit among patients with heart failure [12]. 
Table 1 Summary of the studies

\begin{tabular}{|c|c|c|c|}
\hline tudy & CONFIDENCE II $[15]$ & ROTECT I [17] & PROTECT III [16] \\
\hline & $\begin{array}{l}\text { Effectiveness of hOme blood } \\
\text { pressure monitoring and } \\
\text { educatioNal material For the } \\
\text { control of mIld to moDerate } \\
\text { hypertEnsioN with Coversyl in } \\
\text { a Canadian real-life routine } \\
\text { mEdical practice II }\end{array}$ & $\begin{array}{l}\text { Effectiveness of PeRindOpril in the } \\
\text { management of hyperTension: } \\
\text { idEntification of patient and } \\
\text { physiCian determinants of } \\
\text { response to Treatment } \\
\text { (PROTECT study) }\end{array}$ & $\begin{array}{l}\text { Effectiveness of a support program } \\
\text { designed to sensitize and assist } \\
\text { patients with mild to moderate } \\
\text { hypertension treated with } \\
\text { perindopril to decrease their salt } \\
\text { consumption }\end{array}$ \\
\hline $\begin{array}{l}\text { No. of } \\
\text { patients }\end{array}$ & 13,886 & 15,665 & 12 \\
\hline $\begin{array}{l}\text { Study } \\
\text { period }\end{array}$ & $2008-2010$ & 2009 & 2011 \\
\hline $\begin{array}{l}\text { clusion } \\
\text { criteria }\end{array}$ & $\begin{array}{l}\text { Patients with mild to moderate hy } \\
\text { as: } \\
140 \leq \mathrm{SBP} \leq 179 \mathrm{mmHg} \text { and } 9 \\
\text { (Patients with diabetes: } 130 \leq \mathrm{SH} \\
\text { If previously treated with ACE in }\end{array}$ & $\begin{array}{l}\text { ertension, previously treated (not wit } \\
\leq \mathrm{DBP} \leq 109 \mathrm{mmHg} \\
\mathrm{P} \leq 179 \mathrm{mmHg} \text { and } 80 \leq \mathrm{DBP} \leq \\
\text { hibitors or } \mathrm{ARB} \text { and not controlled, }\end{array}$ & $\begin{array}{l}\text { h perindopril) or not treated, defined } \\
109 \mathrm{mmHg} \text { ) } \\
\text { switch to perindopril }\end{array}$ \\
\hline $\begin{array}{l}\text { Non- } \\
\text { inclusion } \\
\text { criteria }\end{array}$ & $\begin{array}{l}\text { Diagnosed with unstable CAD } \\
\text { History of MI occurring less than } \\
\text { Uncontrolled, treated hypertensio }\end{array}$ & $\begin{array}{l}1 \text { month prior to study entry } \\
\text { : SBP }>179 \mathrm{mmHg} \text { and/or DBP > }\end{array}$ & $109 \mathrm{mmHg}$ while on treatment \\
\hline Treatment & \multicolumn{3}{|c|}{ BP and safety assessment at inclusion (visit 1), after 1 month (visit 2 ), and after 4 months (visit 3 ) } \\
\hline
\end{tabular}

Evidence for the benefits of the combination of perindopril with a beta-blocker has been provided by the results from EUROPA trial $[10,13]$ and by a retrospective pooled analysis of patients from three large perindopril outcome trials (EUROPA, ADVANCE, and PROGRESS) [14], but data on the specific combination of perindopril with bisoprolol are scarce.

This post hoc analysis was performed in a subpopulation of patients selected from a large database from three observational studies that examined the efficacy and tolerability of perindopril in patients with hypertension receiving treatment with other antihypertensive agents, including beta-blockers, in a realworld setting. In the present analysis, we focused on the subpopulation of patients treated with perindopril on top of bisoprololbased therapy.

\section{METHODS}

\section{Study Design}

This post hoc analysis was performed using data from three previously published [15-17], openlabel, prospective, multicenter, observational studies: CONFIDENCE II, PROTECT I, and PROTECT III, conducted across Canada. All shared the same inclusion and exclusion criteria, treatment duration, and primary outcome (Table 1). This post hoc analysis of the individual and combined studies focused on the 
subpopulation of patients treated with perindopril on top of bisoprolol-based therapy.

In these studies, the decision to treat patients with perindopril was independent of study participation and was decided by the treating physicians prior to enrollment. After the physician's decision to prescribe perindopril, a voluntary informed consent form was obtained from the patient to initiate participation into the study.

\section{Compliance with Ethics Guidelines}

This was a post hoc analysis of previously conducted studies. The individual studies were conducted according to the Declaration of Helsinki and Ethical Principles for Medical Research Involving Human Subjects. Before the start of the studies, the protocol, informed consent form, and all other appropriate study documents were submitted to an independent central research ethics committee for review and approval. Studies were approved by the Canadian Shield Ethics Review Board.

\section{Patient Population}

All three studies shared the same inclusion and exclusion criteria, namely patients with untreated or uncontrolled mild-to-moderate hypertension defined according to the Canadian Hypertension Education Program (CHEP) guidelines in force at the time of inclusion $(140 \leq \mathrm{SBP} \leq 179 \mathrm{mmHg}$ and/or $90 \leq \mathrm{DBP} \leq$ $109 \mathrm{mmHg}$, or $130 \leq \mathrm{SBP} \leq 179 \mathrm{mmHg}$ and/or $80 \leq \mathrm{DBP} \leq 109 \mathrm{mmHg}$ in the presence of diabetes mellitus, renal disease, or proteinuria) [18-20], aged at least 18 years of age, without unstable CAD or recent (less than 1 month before participation) myocardial infarction. All patients were followed for 16 weeks and underwent three visits: baseline (visit 1), week 4 (visit 2), and week 16 (visit 3). Patients treated previously with an ACE inhibitor or an ARB and not controlled could be switched to perindopril at the time of study entry according to the judgement of the treating physician. For these patients, the initial dose of perindopril was that considered appropriate by the treating physician and, if BP control was not achieved at 4 weeks, perindopril was uptitrated to $8 \mathrm{mg} /$ day, for the following 12 weeks. The specific populations of patients over 70 years of age and patients with renal impairment received a dose of $2 \mathrm{mg}$ of perindopril tert-butylamine (perindopril tert-butylamine $4 \mathrm{mg}$ and $8 \mathrm{mg}$ corresponds to $5 \mathrm{mg}$ and $10 \mathrm{mg}$ of perindopril arginine, respectively). Perindopril either directly replaced all previous ACE inhibitors or ARBs or was added to antihypertensive treatment with CCBs, diuretics, or $\beta$-adrenoceptor antagonists (beta-blockers).

All patients included in this analysis received treatment with bisoprolol. The most frequent bisoprolol dose at baseline was $5 \mathrm{mg} /$ day, followed by $2.5 \mathrm{mg}$ and $10 \mathrm{mg}$.

\section{Outcome Measures}

The primary outcomes for these post hoc analyses were mean changes in BP from baseline following treatment with perindopril 4 and $8 \mathrm{mg} /$ day on top of bisoprolol-based therapy as well as the proportion of patients achieving BP control $(<140 / 90 \mathrm{mmHg}$, or $<140 / 85 \mathrm{mmHg}$ in patients with diabetes according to the thresholds recommended in European ESH/ESC guidelines [21]) in the intent-to-treat populations. Adverse events were monitored throughout the studies.

BP was measured at each visit after the patient had been seated for at least $5 \mathrm{~min}$, according to a standardized BP measurement protocol, which was provided to all study sites. The average of two BP measurements, taken 5 min apart, was used to assess BP control.

Safety was assessed by reports of emergent adverse events (EAEs), and emergent serious adverse events (ESAEs) at visits 2 (4 weeks) and 3 (16 weeks).

\section{Statistical Methods}

Descriptive statistics, including the mean and standard deviation (SD) for continuous variables, and frequency distributions for categorical variables, were produced for patient demographics and baseline characteristics on the full analysis set (FAS), comprising all patients receiving concomitant perindopril and bisoprolol at baseline who had at least one follow-up BP measurement while on free 


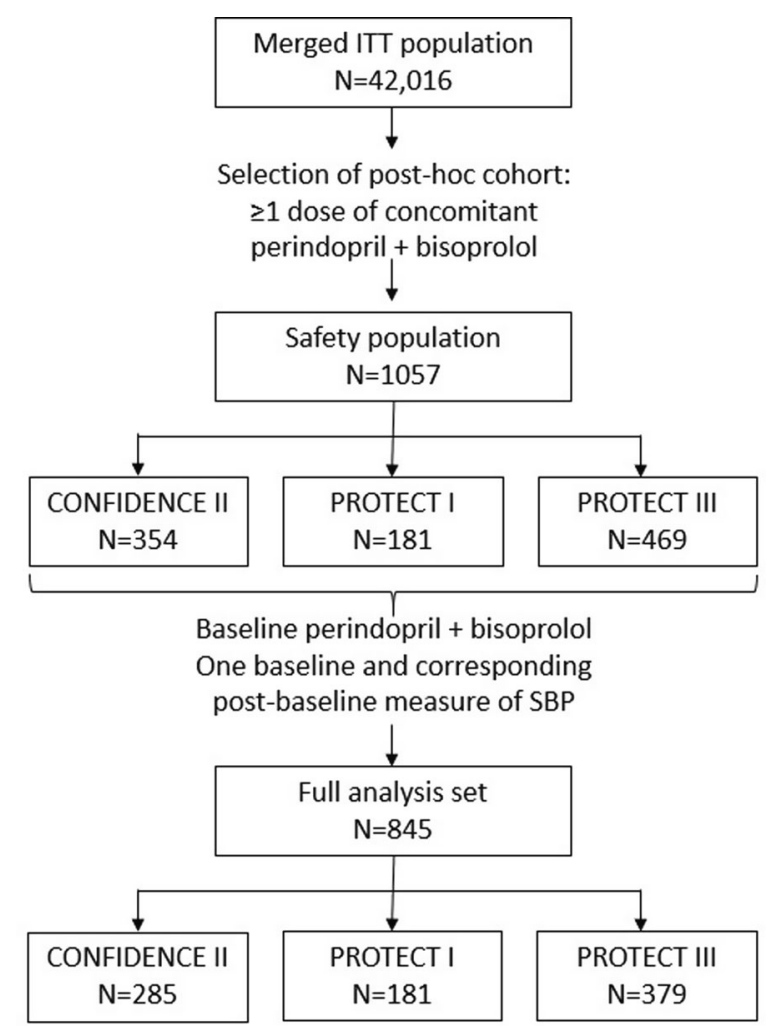

Fig. 1 Patient flow chart

combination treatment. Efficacy analyses were performed on the FAS. Absolute changes in SBP and DBP to visit 3 were conducted applying the last observation carried forward (LOCF) method, with missing SBP or DBP data at visit 3 imputed from visit 2 values. Safety analyses were performed on the safety set, which included all patients receiving concomitant perindopril and bisoprolol at least once during follow-up.

\section{RESULTS}

\section{Baseline Characteristics}

The merged population included 42,248 patients: 13,886 from the CONFIDENCE II study [15], 15,665 from the PROTECT I study [17], and 12,697 from the PROTECT III study [16]. Among them, 4357 patients received at least one dose of concomitant perindopril and beta-blocker, of whom 1057 patients received bisoprolol as beta-blocker, 845 (with at least one baseline and one corresponding post-baseline measurement of SBP) were included in the FAS (Fig. 1), and 713 (84.4\%) received perindopril and bisoprolol for the 16-week study duration. During the trials, 132 patients $(15.6 \%)$ withdrew: 121 were lost to follow-up, 9 due to adverse events, and 2 due to other reasons.

The main demographic and baseline characteristics of patients are presented in Table 2 . The studied population (mean age $68.3 \pm 11.3$ years) had a high proportion of patients over 60 years old (79\%) and had a mean body mass index of $29.4 \pm 5.7 \mathrm{~kg} / \mathrm{m}^{2}$. Mean baseline BP was 151.5/86.0 mmHg overall versus $155.1 / 88.0 \mathrm{mmHg}, \quad 147.2 / 83.7 \mathrm{mmHg}$, and $150.8 / 85.6 \mathrm{mmHg}$ observed in the CONFIDENCE II, PROTECT I, and PROTECT III studies, respectively.

\section{Treatment Dose}

Across all three studies, the most frequent starting dose of perindopril at baseline was $4 \mathrm{mg} /$ day $(60.7 \%)$, followed by $2 \mathrm{mg} /$ day (17.4\%) and $8 \mathrm{mg} /$ day (14.1\%), and for bisoprolol it was $5 \mathrm{mg} /$ day $(56 \%)$, followed by $2.5 \mathrm{mg}(19.3 \%)$ and $10 \mathrm{mg}(18.4 \%)$.

When bisoprolol and perindopril were coadministered, the most frequent doses received throughout these studies were $5 \mathrm{mg}+4 \mathrm{mg}$ $(n=74 ; 30.2 \%)$, and $5 \mathrm{mg}+8 \mathrm{mg} \quad(n=58$; $23.7 \%$ ). Other dosages were $2.5 \mathrm{mg}+4 \mathrm{mg}$ (11.4\%), $10 \mathrm{mg}+10 \mathrm{mg}(9.4 \%), 10 \mathrm{mg}+5 \mathrm{mg}$ (8.2\%), and $2.5 \mathrm{mg}+2 \mathrm{mg}(2 \%)$. Other concomitant antihypertensive treatments [CCBs $(36.7 \%)$ and diuretics (29.8\%)] remained unchanged during the study (Table 2).

\section{Effect of Treatment on Blood Pressure Parameters}

In the subpopulation of patients receiving perindopril on top of bisoprolol-based therapy (merged data from three studies), a significant SBP decrease from baseline was observed at visit $2 \quad(-14.7 \pm 12.3 \mathrm{mmHg}, \quad P<0.001)$; the decrease in DBP of $-6.7 \pm 8.2 \mathrm{mmHg}$ did not reach statistical significance $(P=0.059)$. The $\mathrm{BP}$ change at visit 3 (LOCF) versus baseline $(-19.5 \pm 12.9 /-9.2 \pm 8.9, \quad P<0.001) \quad$ was 
Table 2 Baseline demographic and patient characteristics by study and for the merged full analysis set

\begin{tabular}{|c|c|c|c|c|}
\hline & $\begin{array}{l}\text { CONFIDENCE II [15] } \\
(N=285)\end{array}$ & $\begin{array}{l}\text { PROTECT I [17] } \\
(N=181)\end{array}$ & $\begin{array}{l}\text { PROTECT III [16] } \\
(N=379)\end{array}$ & $\begin{array}{l}\text { Merged FAS } \\
(N=845)\end{array}$ \\
\hline $\begin{array}{l}\text { Men/women, } \\
n(\%)\end{array}$ & $139(49.1) / 144(50.9)$ & $107(59.4) / 73(40.6)$ & $207(55.2) / 168(44.8)$ & $\begin{array}{l}453(54.1) / 385 \\
(45.9)\end{array}$ \\
\hline $\begin{array}{l}\text { Mean age } \pm \text { SD } \\
\quad(\text { years })\end{array}$ & $68.0 \pm 10.8$ & $65.6 \pm 11.0$ & $69.8 \pm 11.5$ & $68.3 \pm 11.3$ \\
\hline Age range (years) & $27.5-92.5$ & $38.7-91.6$ & $31.0-95.0$ & $27.5-95.0$ \\
\hline \multicolumn{5}{|c|}{ Age category (\% patients) } \\
\hline$\leq 39$ years & 1.1 & 0.6 & 0.8 & 0.8 \\
\hline $40-59$ years & 19.3 & 27.1 & 17.7 & 20.2 \\
\hline $60-79$ years & 63.2 & 61.9 & 57.8 & 60.5 \\
\hline$>79$ years & 16.5 & 10.5 & 23.7 & 18.5 \\
\hline $\mathrm{BMI}$, mean $\pm \mathrm{SD}$ & $29.3 \pm 5.6$ & $28.7 \pm 4.8$ & $29.9 \pm 6.1$ & $29.4 \pm 5.7$ \\
\hline $\mathrm{SBP}$, mean $\pm \mathrm{SD}$ & $155.1 \pm 12.3$ & $147.2 \pm 9.9$ & $150.8 \pm 8.3$ & $151.5 \pm 10.6$ \\
\hline $\mathrm{DBP}$, mean $\pm \mathrm{SD}$ & $88.0 \pm 9.8$ & $83.7 \pm 8.2$ & $85.6 \pm 8.7$ & $86.0 \pm 9.1$ \\
\hline \multicolumn{5}{|c|}{ Concomitant antihypertensive treatment, $n$ (\%) } \\
\hline $\mathrm{CCB}$ & $130(45.6)$ & $46(25.4)$ & $134(35.4)$ & $310(36.7)$ \\
\hline Diuretics & $119(41.8)$ & $67(37.0)$ & $66(17.4)$ & $252(29.8)$ \\
\hline
\end{tabular}

similar to the reduction observed at visit 3 (Table 3). Figures 2a, b illustrate the mean change in SBP and DBP for each study and in the merged FAS.

After 16 weeks of treatment, when data from the three study cohorts were combined, over three quarters of patients (78.0\%) achieved the target BP. The corresponding proportions with BP control in the individual studies were $60.4 \%$ of patients in CONFIDENCE II, $88.0 \%$ in PROTECT I, and $86.3 \%$ in PROTECT III. The proportion of patients achieving target BP goals by visit are shown in Fig. 3.

Over the course of the studies there were no statistically significant changes in heart rate.

\section{Safety Analysis}

In the merged safety population, of the 1057 patients who received concomitant treatment with perindopril and bisoprolol, 7.1\% reported at least one emergent adverse event: mostly cough $(3.5 \%)$, headache $(0.9 \%)$, dizziness $(0.8 \%)$, and hypotension $(0.4 \%)$ (Table 4$)$. No serious adverse events were reported in any of the patients.

In the individual studies, at least one emergent adverse event was reported in $9 \%, 9 \%$, and $4.7 \%$ of patients in CONFIDENCE II, PROTECT I, and PROTECT III, respectively.

A total of $1.1 \%$ of patients discontinued treatment because of an adverse event: six patients in CONFIDENCE II, two in PROTECT I, and one in PROTECT II. Reasons for withdrawals were cough in four patients, hypotension in one patient, constipation in one patient, headache in one patient, and dysphagia in one patient; for one patient in PROTECT I the reason was unknown. 
Table 3 Mean absolute changes in SBP and DBP from baseline in the individual studies and in the full analysis set

\begin{tabular}{|c|c|c|c|c|c|}
\hline $\begin{array}{l}\text { Mean change } \pm \text { SD } \\
(\mathrm{mmHg})\end{array}$ & $\begin{array}{l}\text { CONFIDENCE II [15] } \\
(n=285)\end{array}$ & $\begin{array}{l}\text { PROTECT I [17] } \\
(n=181)\end{array}$ & $\begin{array}{l}\text { PROTECT III }[16] \\
(n=379)\end{array}$ & $\begin{array}{l}\text { FAS } \\
(n=845)\end{array}$ & $\begin{array}{l}P \\
\text { value* }\end{array}$ \\
\hline \multicolumn{6}{|c|}{ Systolic blood pressure $(\mathrm{mmHg})$} \\
\hline$n$ & 282 & 181 & 368 & 831 & \\
\hline Visit 2- baseline & $-13.6 \pm 14.4$ & $-12.8 \pm 12.7$ & $-16.4 \pm 10.1$ & $-14.7 \pm 12.3$ & $<0.001$ \\
\hline$n$ & 235 & 167 & 299 & 701 & \\
\hline Visit 3 - baseline & $-18.8 \pm 15.1$ & $-16.4 \pm 11.8$ & $-23.9 \pm 10.4$ & $-20.4 \pm 12.9$ & $<0.001$ \\
\hline $\mathrm{N}$ & 284 & 181 & 379 & 844 & \\
\hline LOCF - baseline & $-17.8 \pm 14.9$ & $-16.8 \pm 12.0$ & $-22.1 \pm 11.1$ & $-19.5 \pm 12.9$ & $<0.001$ \\
\hline \multicolumn{6}{|c|}{ Diastolic blood pressure $(\mathrm{mmHg})$} \\
\hline $\mathrm{N}$ & 282 & 181 & 368 & 831 & \\
\hline Visit 2 - baseline & $-6.8 \pm 9.9$ & $-5.9 \pm 6.9$ & $-6.9 \pm 7.3$ & $-6.7 \pm 8.2$ & 0.059 \\
\hline $\mathrm{N}$ & 235 & 167 & 299 & 701 & \\
\hline Visit 3 - baseline & $-9.0 \pm 9.9$ & $-6.7 \pm 7.9$ & $-12.1 \pm 7.4$ & $-9.8 \pm 8.7$ & $<0.001$ \\
\hline $\mathrm{N}$ & 284 & 181 & 379 & 844 & \\
\hline LOCF - baseline & $-8.7 \pm 10.1$ & $-7.0 \pm 8.0$ & $-10.6 \pm 8.2$ & $-9.2 \pm 8.9$ & $<0.001$ \\
\hline
\end{tabular}

FAS full analysis set, LOCF last observation carried forward. Visit 2, 4 weeks. Visit 3, 16 weeks ${ }^{*} P$ value for FAS compared with baseline

\section{DISCUSSION}

This retrospective post hoc analysis in a merged patient population from three large observational studies showed that the addition of perindopril to background bisoprolol therapy was associated with statistically significant reductions in BP compared with baseline. The SBP/DBP decrease from baseline after 4 weeks of treatment was $-14.7 \pm 12.3 /-6.7 \pm 8.2 \mathrm{mmHg} \quad(P<0.001)$, with an additional decrease after 16 weeks of treatment $\quad(-20.4 \pm 12.9 /-9.8 \pm 8.7 \mathrm{mmHg}$, $P<0.001)$. Over three quarters $(78 \%)$ of patients in the FAS achieved BP treatment goals at study end.

As expected, analysis of heart rate over the course of the studies revealed no statistically significant changes compared with baseline, as all patients were already receiving bisoprolol at study entry and perindopril has no effect on heart rate. The addition of perindopril to bisoprolol was well tolerated, demonstrating a safety profile similar to that of perindopril and bisoprolol administered as single agents. No unexpected adverse events were observed and there were no serious adverse events.

Beta-blockers and ACE inhibitors represent major therapeutic classes in the management of hypertension, stable CAD, and chronic heart failure, and their position in the therapeutic strategy for these conditions is clearly defined in the respective clinical practice guidelines $[3,21,22]$. In the ESC/ESH guidelines for the management of arterial hypertension, combination treatment is recommended as initial therapy for most patients with hypertension [3]. First-line treatment should comprise a RAS blocker (either an ACE inhibitor or ARB) with a CCB or diuretic, with the option to add a betablocker to any of the other major drug classes when there are specific clinical situations, e.g., angina, post-myocardial infarction, heart failure, or heart rate control. In the ESC guidelines on the management of stable CAD [21, 23], 

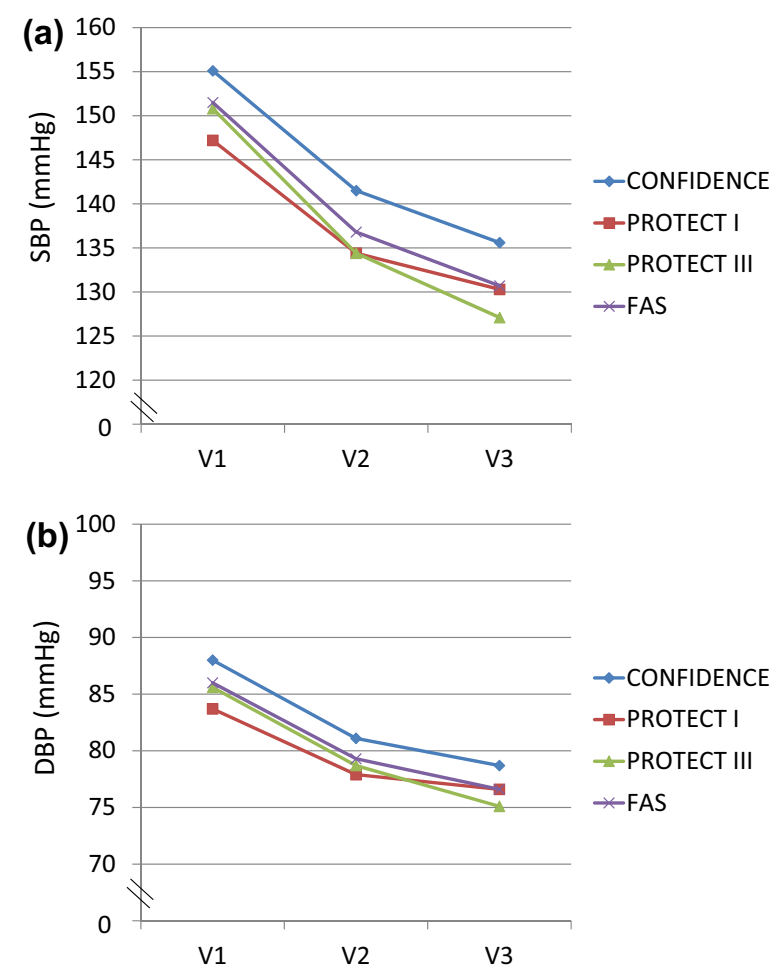

Fig. 2 a Mean SBP and b DBP reductions from baseline to visit 3 ( 16 weeks) in patients receiving concomitant bisoprolol and perindopril

beta-blockers are indicated as first-line treatment to control heart rate and symptoms, whereas ACE inhibitors are recommended to prevent cardiovascular events, especially in the presence of other conditions (e.g., heart failure, hypertension, or diabetes). Finally, the ESC guidelines for the diagnosis and treatment of acute and chronic heart failure state that ACE inhibitors and beta-blockers are treatments recommended in potentially all patients with systolic heart failure [22]. According to the guideline recommendations, the spectrum of patients for whom a beta-blocker combination may be appropriate is therefore quite large.

The benefits of adding perindopril to betablocker therapy were first demonstrated in the EUROPA trial, which randomized 12,218 patients with coronary heart disease to perindopril or placebo for a mean follow-up duration of 4.2 years [10]. Perindopril treatment was associated with a significant $20 \%$ relative risk reduction $(95 \%$ CI $9-29, P=0.0003)$ in the primary endpoint (cardiovascular mortality, non-fatal myocardial infarction, and resuscitated cardiac arrest). The beneficial effect of perindopril on the primary endpoint was also

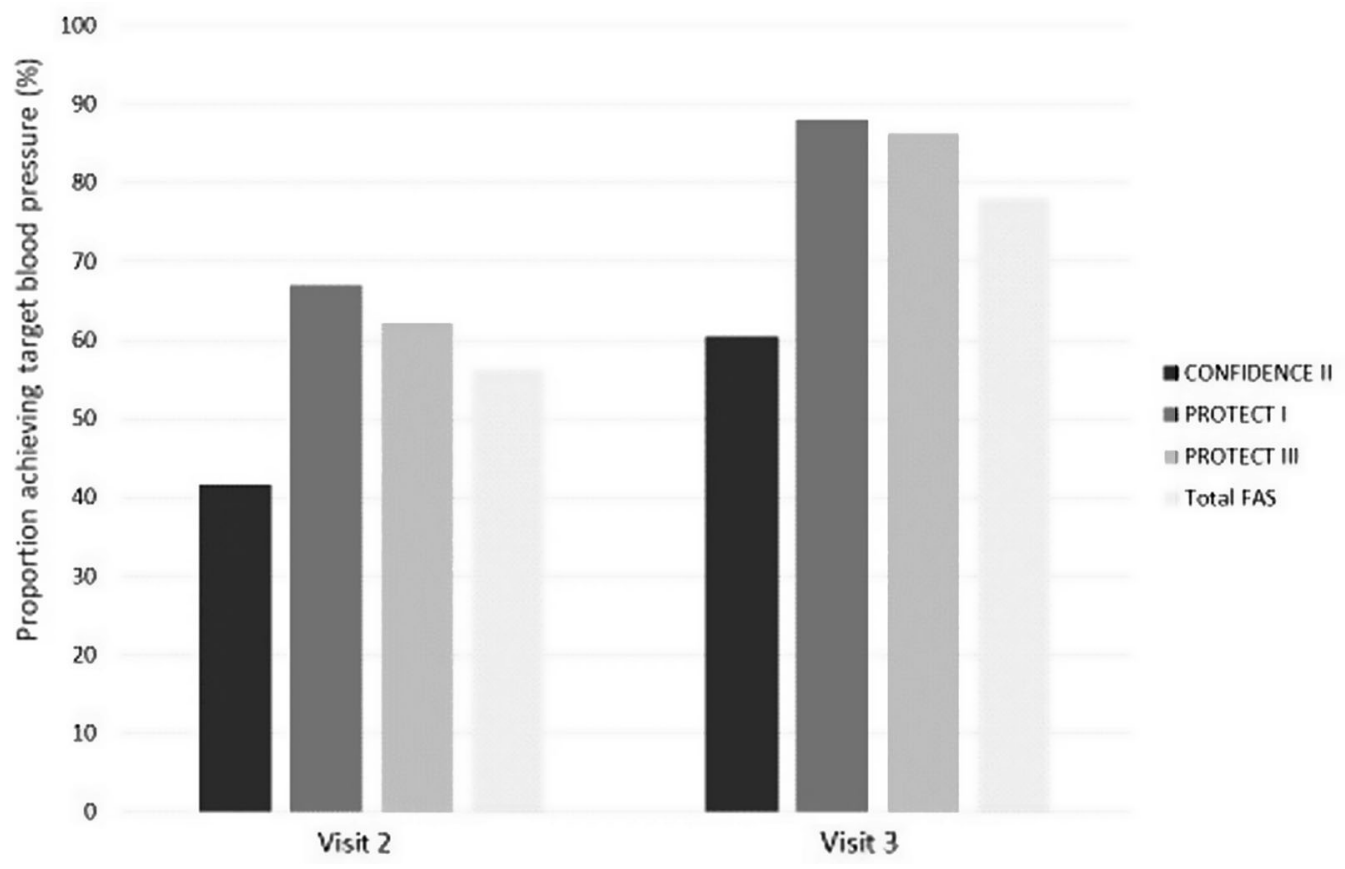

Fig. 3 Proportion of patients achieving target blood pressure $(<140 / 90 \mathrm{mmHg}$ for patients without diabetes, or $<140 /$ $85 \mathrm{mmHg}$ for patients with diabetes) at visit 2 ( 4 weeks) and visit 3 (16 weeks) 
Table 4 Emergent adverse events (EAEs) by study and for merged safety population

\begin{tabular}{lllll}
\hline & $\begin{array}{l}\text { CONFIDENCE II[15] } \\
(\boldsymbol{N}=\mathbf{3 5 4})\end{array}$ & $\begin{array}{l}\text { PROTECT I [17] } \\
(\boldsymbol{N}=\mathbf{2 3 4})\end{array}$ & $\begin{array}{l}\text { PROTECT III [16] } \\
(\boldsymbol{N}=\mathbf{4 6 9})\end{array}$ & $\begin{array}{l}\text { Merged safety } \\
(\boldsymbol{N}=\mathbf{1 0 5 7})\end{array}$ \\
\hline $\begin{array}{l}\text { Total no. of EAEs reported } \\
48\end{array}$ & 24 & 29 & 101 \\
$\begin{array}{l}\text { No. patients reporting } \geq 1 \\
\text { EAE, } n \text { (\%) }\end{array}$ & $32(9.0)$ & $21(9.0)$ & $22(4.7)$ & $75(7.1)$ \\
No. patients reporting most common EAE, $n(\%)$ & & & \\
Cough & $22(6.2)$ & $8(3.4)$ & $7(1.5)$ & $37(3.5)$ \\
Headache & $3(0.8)$ & $4(1.7)$ & $2(0.4)$ & $9(0.9)$ \\
Dizziness & $2(0.6)$ & $2(0.9)$ & $4(0.9)$ & $8(0.8)$ \\
Hypotension & $2(0.6)$ & - & $2(0.4)$ & $4(0.4)$ \\
Hyperhidrosis & - & $2(0.9)$ & - & $2(0.2)$ \\
Palpitations & - & - & $2(0.4)$ & $2(0.2)$ \\
\hline
\end{tabular}

significant in the pre-defined subgroup of patients with beta-blocker therapy at baseline (62\% of the trial population), relative risk reduction $26.4 \%$ (95\% CI 14.3-36.8, $P<0.001$ ).

A further subanalysis of EUROPA, conducted in patients receiving both perindopril and betablockers at randomization and at the time of the event, confirmed a significant reduction in the relative risk for the primary endpoint $(-24 \%$, $P=0.002)$ and secondary endpoints, including myocardial infarction $(-28 \%, P=0.001)$ and hospitalization for heart failure $(-45 \%$, $P=0.025)$, for patients on beta-blocker/ perindopril treatment compared with betablocker/placebo [13].

Other large-scale trials have also provided evidence on cardiovascular outcomes following the addition of perindopril to background betablocker therapy. These have been conducted among patients with previous stroke or ischemic attack (PROGRESS, 17\% receiving beta-blocker [9]) and type 2 diabetes (ADVANCE, 25\% receiving beta-blocker [11]). A subsequent retrospective pooled analysis of PROGRESS, EUROPA, and ADVANCE reported a decreased risk of the primary composite endpoint of cardiovascular mortality, non-fatal MI, and stroke $(-20 \%, 95 \%$ CI $0.71-0.90)$, as well as the secondary endpoints of non-fatal MI (-23\%, 95\% CI 0.65-0.91) and all-cause mortality (-22\%, 95\% CI 0.68-0.88) for patients on perindopril and background beta-blocker therapy compared with beta-blocker/placebo [14].

Within the beta-blocker class, individual agents have a number of pharmacological differences, such as beta-adrenergic selectivity, lipid solubility, and dual receptor activity, which make each agent unique. Among the cardioselective beta-blockers, bisoprolol has the greatest affinity for the cardiac $\beta_{1}$-adrenoceptor and is less likely to cause constriction of airways or peripheral vasculature [24]. Bisoprolol is also highly absorbed after oral administration, has a half-life in plasma of $10-12 \mathrm{~h}$ that gives a $24-\mathrm{h}$ effect dosing once daily, and is eliminated by both hepatic and renal routes [25]. The last of these means that it does not require dose adjustments for patients with either renal or liver dysfunction, and is also less likely to interact with other medicines. Among the betablockers, bisoprolol was the first to demonstrate improved survival in a cardiovascular outcome trial, with a $34 \%$ relative risk reduction in allcause mortality in patients with heart failure with reduced ejection fraction and NYHA class III-IV symptoms when added to standard 
therapy including ACE inhibitors and diuretics [12].

Compared with other ACE inhibitors, perindopril has higher lipophilicity, stronger tissue ACE-inhibiting properties, and the highest selectivity for bradykinin versus angiotensin I binding sites, leading to enhancement of nitric oxide and inhibition of endothelial cell apoptosis [26, 27]. Perindopril has a 24-h duration of action and trough effects are about $87-100 \%$ of peak effects [28].

There is therefore considerable rationale for combining perindopril with beta-blockers, and in particular, bisoprolol. However, to date, the evidence base regarding the effectiveness and safety of a combination of a BB with ACEI in the treatment of patients with hypertension based on clinical trials is very small. A search of the literature for data on perindopril/bisoprolol combinations identified a few relevant studies. An exploratory study in patients with hypertension, which examined BP lowering and inflammatory markers after 4 weeks of treatment with perindopril, bisoprolol, or a perindopril/bisoprolol combination, found that perindopril reduced mean 24-h SBP/DBP by $-15.9 /-8 \mathrm{mmHg}$, while the bisoprolol and perindopril combination caused a more pronounced decrease of $-24.9 /-16.2 \mathrm{mmHg}$ [29]. A small-scale study, which compared an ACE inhibitor/atenolol with an ACE inhibitor/bisoprolol combination, reported greater BP lowering and achievement of target with the bisoprolol combination [30].

As combination therapy is now recommended in most patients, it is important to evaluate the effectiveness and safety of combination treatments in a wide spectrum of patients with different disease severity and duration that will be encountered in clinical practice.

In a Canadian observational study in patients with hypertension and additional cardiovascular risk factors [31], the addition of perindopril to the subgroup of patients who were on beta-blocker therapy at baseline resulted in a reduction in mean SBP/DBP of $-22.1 /-9.7 \mathrm{mmHg}$ after 10 weeks of treatment. Furthermore, a large retrospective database analysis found that among patients uncontrolled on beta-blocker therapy, the addition of an ACE inhibitor resulted in an additional reduction in SBP of $-16 \mathrm{mmHg}$ and in DBP of $-4.9 \mathrm{mmHg}$ [32].

Our post hoc analysis provides data on a population of 845 patients receiving perindopril on top of background bisoprolol therapy, showing a SBP/DBP decrease of $-20.4 \pm 12.9 /-9.8 \pm 8.7 \mathrm{mmHg}, \quad P<0.001$ after 16 weeks of treatment. The most important BP decrease was observed in PROTECT III, and it is worth noting that in this study patients followed a support program to decrease their salt consumption, which is known to have an impact on BP decrease, and which is a lifestyle modification recommended by guidelines.

Effective and well-established treatments are available for the management of hypertension and hypertension-mediated organ disease, so efforts are now increasingly focused on improving treatment implementation and tailoring treatment to patient needs. The availability of two-drug single-pill combinations (SPC) is currently mainly limited to a RAS blocker with either a CCB or diuretic, and the ESC/ESH guidelines emphasize that it would be desirable to see the development of an expanded range of SPCs in different drug formulations, tailored to different clinical requirements.

The first SPC of bisoprolol and perindopril became available in 2016 in the form of bisoprolol/perindopril $\left(\right.$ Cosyrel $\left.^{\circledR}\right)$, which facilitates meeting guideline recommendations to use a single-pill-based treatment strategy whenever possible [3].

Real-world data on the benefits of using a bisoprolol/perindopril SPC in patients with hypertension and stable CAD (previously treated with bisoprolol with or without concomitant perindopril) were obtained from two recent open-label, prospective, observational studies $[33,34]$. Patients were treated with SPC for 1 month $(n=2394)$ and 3 months $(n=1892)$, respectively. The results of both studies support the addition of a bisoprolol/perindopril SPC to standard antihypertensive therapy to simultaneously reduce BP and heart rate in patients with hypertension and stable $\mathrm{CAD}$, and to allow more patients to achieve BP treatment goals. The beneficial effects of the SPC on these risk 
factors were accompanied by improvements in angina symptoms and quality of life. Furthermore, the treatment was well tolerated in a broad patient population representative of those seen in everyday clinical practice. In the present analysis, we also observed a high prevalence of patients with CAD (61\%), suggesting that the finding might be relevant to this patient population. Unfortunately, we did not collect data on other comorbidities that would allow us to conclude on the benefits of this combination in specific patient profiles.

Recent European hypertension guidelines included resting $\mathrm{HR}>80 \mathrm{bpm}$ among $\mathrm{CV}$ risk factors [3], and BB are the main drug class acting on HR. This combination has indeed a strong rationale in patients with chronic marked sympathetic nervous system overactivity and RAAS overstimulation, especially those with elevated HR.

The results of this post hoc analysis are limited by the observational nature of the individual studies included; more specifically, the lack of a comparator arm and randomization. In addition, patients were on a range of antihypertensive medications at baseline including CCBs and diuretics, which could be continued for the duration of the trial. Similar to the retrospective pooled analysis of the ADVANCE, EUROPA, and PROGRESS pivotal clinical trials [14], the current analysis was strengthened by only including studies with similar designs. A major limitation of the current post hoc analysis was related to the cutoff used for the achievement of target BP in patients with diabetes. This was updated to reflect the $2013 \mathrm{ESC} /$ ESH recommendation current at the time of the analysis (140/85 $\mathrm{mmHg}$ ) [21], but as the 2012 CHEP guideline thresholds were implemented in the individual studies, this led to protocoldefined uncontrolled hypertension in patients with diabetes being established at BPs $\geq 130$ / $80 \mathrm{mmHg}$. As a result, 234 patients with diabetes were considered to have controlled hypertension at baseline (visit 1) due to the post hoc adoption of the 2013 ESC/ESH targets. Although included in the individual and merged safety and FAS populations, these patients were excluded from the target BP analyses in order to provide a more accurate representation of BP control.

\section{CONCLUSIONS}

The results of this retrospective post hoc analysis of three large observational studies show that addition of perindopril on top of bisoprolol-based therapy is commonly prescribed in routine clinical practice for patients with mildto-moderate hypertension. Treatment effectiveness was confirmed by significant reductions in BP compared with baseline and achievement of BP targets by $78 \%$ of patients. The addition of perindopril to background bisoprolol was well tolerated, making it a safe and effective therapy option for patients in routine clinical practice.

\section{ACKNOWLEDGEMENTS}

Funding. The Journal's Rapid Service and open access fees were funded by Servier, France.

Medical Writing and/or Editorial Assistance. Medical writing support was provided by Jenny Grice and funded by Servier, France.

Authorship. All named authors meet the International Committee of Medical Journal Editors (ICMJE) criteria for authorship for this article, take responsibility for the integrity of the work as a whole, and have given their approval for this version to be published.

Author Contributions. All authors contributed to this analysis, revised and approved drafts of the manuscript, and take responsibility for the accuracy of the data.

Disclosures. Murielle Abeel is an employee of Servier (France). Anil Gupta declares honoraria from Servier, Bayer, Amgen, BMS/Pfizer, and Boehringer Ingelheim. Christian Constance has received honoraria from AstraZeneca, Servier, Amgen, and Bayer. 
Compliance with Ethics Guidelines. This was a post hoc analysis of previously conducted studies. The individual studies were conducted according to the Declaration of Helsinki and Ethical Principles for Medical Research Involving Human Subjects. After the physician's decision to prescribe perindopril, a voluntary informed consent form was obtained from the patient to initiate participation into the study. Before the start of the studies, the protocol, informed consent form, and all other appropriate study documents were submitted to an independent central research ethics committee for review and approval. Studies were approved by the Canadian Shield Ethics Review Board. After the physician's decision to prescribe perindopril, a voluntary informed consent form was obtained from the patient to initiate participation into the study.

Data Availability. The datasets generated during and/or analyzed during the current study are available from the corresponding author on reasonable request.

Open Access. This article is licensed under a Creative Commons Attribution-NonCommercial 4.0 International License, which permits any non-commercial use, sharing, adaptation, distribution and reproduction in any medium or format, as long as you give appropriate credit to the original author(s) and the source, provide a link to the Creative Commons licence, and indicate if changes were made. The images or other third party material in this article are included in the article's Creative Commons licence, unless indicated otherwise in a credit line to the material. If material is not included in the article's Creative Commons licence and your intended use is not permitted by statutory regulation or exceeds the permitted use, you will need to obtain permission directly from the copyright holder. To view a copy of this licence, visit http://creativecommons.org/licenses/by$\mathrm{nc} / 4.0 /$.

\section{REFERENCES}

1. Corrao G, Nicotra F, Parodi A, et al. Cardiovascular protection by initial and subsequent combination of antihypertensive drugs in daily life practice. Hypertension. 2011;58(4):566-72.

2. Whelton PK, Carey RM, Aronow WS, et al. 2017 ACC/AHA/AAPA/ABC/ACPM/AGS/APhA/ASH/ ASPC/NMA/PCNA guideline for the prevention, detection, evaluation, and management of high blood pressure in adults: executive summary: a report of the American College of Cardiology/ American Heart Association Task Force on Clinical Practice Guidelines. J Am Coll Cardiol. 2018;71(19): 2199-269.

3. Williams B, Mancia G, Spiering W, et al. 2018 ESC/ ESH guidelines for the management of arterial hypertension. Eur Heart J. 2018;39(33):3021-104.

4. Wald DS, Law M, Morris JK, et al. Combination therapy versus monotherapy in reducing blood pressure: meta-analysis on 11,000 participants from 42 trials. Am J Med. 2009;122:290-300.

5. Persu A, Lopez-Sublet M, Algharably EAE, Kreutz R. Starting antihypertensive drug treatment with combination therapy: controversies in hypertension-pro side of the argument. Hypertension. 2021;77(3):800-5.

6. Kotseva K, De Backer G, De Bacquer D, et al. Lifestyle and impact on cardiovascular risk factor control in coronary patients across 27 countries: Results from the European Society of Cardiology ESC-EORP EUROASPIRE V registry. Eur J Prev Cardiol. 2019;26(8):824-35.

7. Maggioni AP, Anker SD, Dahlström U, et al. Are hospitalized or ambulatory patients with heart failure treated in accordance with European Society of Cardiology guidelines? Evidence from 12,440 patients of the ESC Heart Failure Long-Term Registry. Eur J Heart Fail. 2013;15(10):1173-84.

8. Thoenes M, Neuberger HR, Volpe M, Khan BV, Kirch W, Böhm M. Antihypertensive drug therapy and blood pressure control in men and women: an international perspective. J Hum Hypertens. 2010;24(5):336-44.

9. PROGRESS Collaborative group. Randomised trial of a perindopril-based blood-pressure-lowering regimen among 6105 individuals with previous stroke or transient ischaemic attack. Lancet. 2001;358(9287):1033-41.

10. Fox KM. EURopean trial On reduction of cardiac events with Perindopril in stable coronary Artery disease Investigators. Efficacy of perindopril in 
reduction of cardiovascular events among patients with stable coronary artery disease: randomised, double-blind, placebo-controlled, multicentre trial (the EUROPA study). Lancet. 2003;362(9386): 782-8.

11. Patel A, MacMahon S, Chalmers J, et al. Effects of a fixed combination of perindopril and indapamide on macrovascular and microvascular outcomes in patients with type 2 diabetes mellitus (the ADVANCE trial): a randomised controlled trial. Lancet. 2007;370(9590):829-40.

12. CIBIS-II Investigators and Committees. The cardiac insufficiency Bisoprolol Study II (CIBIS-II): a randomised trial. Lancet. 1999;353(9146):9-13.

13. Bertrand ME, Ferrari R, Remme WJ, Simoons ML, Fox KM. Perindopril and $\beta$-blocker for the prevention of cardiac events and mortality in stable coronary artery disease patients: A EUropean trial on Reduction Of cardiac events with Perindopril in stable coronary Artery disease (EUROPA) subanalysis. Am Heart J. 2015;170(6):1092-8.

14. Brugts JJ, Bertrand M, Remme W, et al. The treatment effect of an ACE-inhibitor based regimen with perindopril in relation to beta-blocker use in 29,463 patients with vascular disease: a combined analysis of individual data of ADVANCE, EUROPA and PROGRESS trials. Cardiovasc Drugs Ther. 2017;31(4):391-400.

15. Tsoukas G, Anand S, Yang K. Dose-dependent antihypertensive efficacy and tolerability of perindopril in a large, observational, 12-week, general practice-based study. Am J Cardiovasc Drugs. 2011;11(1):45-55.

16. Jain S, Birbrager DR, Kumar N, Sampalis J. Effectiveness of a support program designed to sensitize and assist hypertensive patients to decrease their salt consumption. J Hypertens. 2014;32(suppl1): e61-2.

17. Jain S, Boucher D, Chen JSL. Effectiveness of perindopril in the management of hypertension: identification of patient and physician determinants of response to treatment. J Hypertens. 2014;32(e-suppl.1):e342.

18. Campbell NR, Khan NA, Hill MD, et al. 2009 Canadian Hypertension Education Program recommendations: the scientific summary-an annual update. Can J Cardiol. 2009;25(5):271-7.

19. Campbell NR, Kaczorowski J, Lewanczuk RZ, et al. 2010 Canadian Hypertension Education Program (CHEP) recommendations: the scientific summary an update of the 2010 theme and the science behind new CHEP recommendations. Can J Cardiol. 2010;26(5):236-40.
20. Campbell NR, Poirier L, Tremblay G, Lindsay P, Reid D, Tobe SW. Canadian Hypertension Education Program: the science supporting new 2011 CHEP recommendations with an emphasis on health advocacy and knowledge translation. Can J Cardiol. 2011;27(4):407-14.

21. Montalescot G, Sechtem U, Achenbach S, et al. 2013 ESC guidelines on the management of stable coronary artery disease: the task force on the management of stable coronary artery disease of the European Society of Cardiology. Eur Heart J. 2013;34:2949-3003.

22. McMurray JJ, Adamopoulos S, Anker SD, et al. ESC Committee for Practice Guidelines. ESC Guidelines for the diagnosis and treatment of acute and chronic heart failure 2012: The Task Force for the Diagnosis and Treatment of Acute and Chronic Heart Failure 2012 of the European Society of Cardiology. Developed in collaboration with the Heart Failure Association (HFA) of the ESC. Eur Heart J. 2012;33(14):1787-847.

23. Knuuti J, Wijns W, Saraste A, et al. 2019 ESC Guidelines for the diagnosis and management of chronic coronary syndromes. Eur Heart J. 2020;41(3):407-77.

24. Weber MA. The role of the new beta-blockers in treating cardiovascular disease. Am J Hypertens. 2005;18:169S-176S.

25. Leopold G. Balanced pharmacokinetics and metabolism of bisoprolol. J Cardiovasc Pharmacol. 1986;8(Suppl 11):S16-20.

26. Ceconi C, Francolini G, Olivares A, Comini L, Bachetti T, Ferrari R. Angiotensinconverting enzyme (ACE) inhibitors have different selectivity for brain binding sites of human somatic ACE. Eur J Pharmacol. 2007;577:1-6.

27. Dinicolantonio JJ, Lavie CJ, O'Keefe JH. Not all angiotensin-converting enzyme inhibitors are equal: focus on ramipril and perindopril. Postgrad Med. 2013;125(4):154-68.

28. Vincent M, Redmond G, Portevin B. Stereoselective synthesis of a new perhydroindole derivative of chiral iminodiacid, a potent inhibitor of angiotensin converting enzyme. Tetrahedron Lett. 1982;23:1677.

29. Madej A, Buldak L, Basiak M, Szkrobka W, Dulawa A, Okopien B. The effects of 1 month antihypertensive treatment with perindopril, bisoprolol or both on the ex vivo ability of monocytes to secrete inflammatory cytokines. Int J Clin Pharmacol Ther. 2009;47(11):686-94. 
30. Marazzi G, Campolongo G, Pelliccia F, et al. Bisoprolol better than atenolol as add on therapy to ACE inhibitors in blood pressure control. J Hypertens. $2018 ; 36: 43$.

31. Ogilvie RI, Anand S, Roy P, De Souza S. Perindopril for control of blood pressure in patients with hypertension and other cardiovascular risk factors: an open-label, observational, multicentre, general practice-based study. Clin Drug Investig. 2008;28(11):673-86.

32. Bisognano JD, McLaughlin T, Roberts CS, Tang SS. Calcium channel blockers, angiotensin receptor blockers, and angiotensin-converting enzyme inhibitors: effectiveness in combination with diuretics or beta-blockers for treating hypertension. Vasc Health Risk Manag. 2007;3(5):579-85.

33. Lutai MI, Golikova IP. The effectiveness of treatment of patients with stable coronary heart disease and concomitant arterial hypertension: the results of a multicenter study Prestol. Ukrainian Cardiol Mag. 2019;26(1):13-24.

34. Boytsov SA, Burtsev YP, Khomitskaya YV, Karpov YA. Effectiveness and tolerability of the single-pill combination of bisoprolol and perindopril in patients with arterial hypertension and stable coronary artery disease in daily clinical practice: the STYLE study. Adv Ther. 2021;38(6):3299-313. 